\title{
The suboccipital midline approach to foramen magnum meningiomas; feasible, but is it optimal?
}

\author{
Amir R. Dehdashti
}

Received: 26 February 2015 / Accepted: 3 March 2015 / Published online: 18 March 2015

(C) Springer-Verlag Wien 2015

In this "how I do it", Dr. Della Puppa and colleagues describe a midline sub-occipital approach for an anterolaterally located foramen magnum meningioma. They provide several justifications based on their experience that a simple midline approach is enough to tackle even more anteriorly located pathologies. They further provide a well-illustrated movie showing a nice resection of a foramen magnum meningioma. It seems that the main rationale for their midline approach is a simpler technique, less risk of cranio-vertebral junction instability, and less risk of CSF leak. This approach has been described before and advocated only for very large and giant meningiomas in this location [1].

While I can understand this approach selection point of view, I respectfully disagree with a uniform consideration of a midline sub-occipital approach for anterior and anterolateral foramen magnum meningiomas.

The movie provided, despite a meticulous microsurgical technique, shows some additional manipulations of the brainstem and cranial nerves that could potentially have been avoided had a lateral approach been chosen. One could possibly relate the co-morbidity of post-operative swallowing deficit, and 16-day hospital course to the sub-optimal surgical exposure. Furthermore, if the surgeon drills even minimally the condyle to get the sufficient exposure, the approach should not be called midline, as the approach central focus will be more lateral, regardless of the type of the incision used.

The fact that it is technically feasible to resect such a meningioma by a midline approach does not provide enough evidence to advocate for it as the preferred option. The same is applicable to surgical clipping of a PICA aneurysm. Although a simple retrosigmoid craniotomy will get the surgeon to the pathology, a far lateral approach with an inferior-

A. R. Dehdashti $(\bowtie)$

Northshore University Hospital, Manhasset, NY, USA

e-mail: adehdashti@nshs.edu superior trajectory is more appropriate with less risk of retraction injury to cranial nerves, optimal exposure, and hence a better outcome.

The modern far lateral (or enough lateral) retractor-less approach necessitates no or only minimal drilling of the occipital condyle (less than $20 \%$ ), and the risk of instability is null [2-4]. The CSF leak rate is not greater with lateral approaches if appropriate dural closure is applied. The amount of brainstem manipulation is undeniably less, and the tumor exposure is better with the lateral approach, and furthermore it can also be performed in the sitting position if that is the surgeon's preference. The enhanced retractor-less surgical exposure of the tumor, while preserving the cranial nerves, should dictate the surgical corridor and not the feasibility of a rather simpler approach.

I encourage the authors to provide us with their series of foramen magnum meningiomas treated with the midline approach. This will allow us to objectively evaluate the functional outcomes, complications, and hospital stay and compare to the results of the well-established lateral approach.

\section{References}

1. Gupta SK, Khosla VK, Chhabra R, Mukherjee KK (2004) Posterior midline approach for large anterior/anterolateral foramen magnum tumours. Br J Neurosurg 181(2):164-167

2. Kryzanski JT, Robertson JH, Heilman CB (2014) A minimal access far-lateral approach to foramen magnum lesions. J Neurol Surg B Skull Base 75(4):236-242

3. Nanda A, Vincent DA, Vannemreddy PS, Baskaya MK, Chanda A (2002) Far-lateral approach to intradural lesions of the foramen magnum without resection of the occipital condyle. J Neurosurg 96(2): 302-309

4. Wu Z, Hao S, Zhang J, Zhang L, Jia G, Tang J, Xiao X, Wang L, Wang $Z$ (2009) Foramen magnum meningiomas: experiences in 114 patients at a single institute over 15 years. Surg Neurol 72(4):376-382, discussion 382 